\title{
EVALUATION OF CAVITY DISTRIBUTION USING POINT-PATTERN ANALYSIS
}

\author{
Raghav Ramanathan \\ RIZZO Associates, 500 Penn Center Boulevard, Pittsburgh, PA, 15235, USA, raghav.ramanathan@rizzoassoc.com
}

Yongli Gao

Center for Water Research, Department of Geological Sciences at The University of San Antonio, One UTSA Circle, San Antonio, TX, 78249,USA,yongli.gao@utsa.edu

M. Melih Demirkan

RIZZO Associates, 500 Penn Center Boulevard,Pittsburgh, PA, 15235,USA, melih.demirkan@rizzoassoc.com

Bulent Hatipoglu

RIZZO Associates, 500 Penn Center Boulevard,Pittsburgh,PA, 15235, USA, bulent.hatipoglu@rizzoassoc.com

Mazen Elias Adib

Town Planning Sector, Abu Dhabi City Municipality,P.O.Box 263,Abu Dhabi,UAE, Mazen.Adib@adm.abudhabi.ae

Michael Rosenmeier

RIZZO Associates, 500 Penn Center Boulevard, Pittsburgh, PA, 15235, USA, michael.rosenmeier@rizzoassoc.com

\section{Juan J. Gutierrez}

RIZZO Associates, 500 Penn Center Boulevard, Pittsburgh, PA, 15235, USA, juan.gutierrez@rizzoassoc.com

\section{Hesham El Ganainy}

RIZZO Associates, 500 Penn Center Boulevard, Pittsburgh, PA, 15235, USA, hesham.elganainy@rizzoassoc.com

\begin{abstract}
The presence of solution cavities of different sizes poses major engineering problems in some areas of Abu Dhabi City Municipality (ADM) underlain by soluble rocks such as gypsum, calcarenite, or mudstone. This is especially critical if they are located at a relatively shallow level and are likely to cause settlement or sudden soil collapses. The Gachsaran Formation, which is composed of interlayered mudstone and gypsum, underlies all of the ADM and is known to be vulnerable to cavity formation in the area. Information associated with cavities was cataloged and reviewed based on available data from an existing geotechnical borehole database maintained by the ADM. Cavity data obtained from borehole information were analyzed to examine cavity distributions based on the following factors: lithology, geographic clusters, cavity density, cavity size, depth to cavity, and depth to bedrock. All cavities were grouped into geographic clusters and lithological clusters for point-pattern analysis. Most cavities (87 percent) occur in mudstone or gypsum, or at an interface between these two rock types, which compose part of the Gachsaran Formation. Geographically the majority of cavities occurred in the Shakhbout City area hence pattern analysis
\end{abstract}

including average nearest neighbor analysis, Moran's I for measuring spatial autocorrelation, and G-statistics for measuring high/low clustering were conducted in this area using spatial statistics tools in ArcGIS. Average nearest neighbor analysis and Moran's- I show that cavities are strongly clustered in this area with a high confidence level ( $>99$ percent). General G-statistics identified a high clustering (hot spot) of cavities with relatively high values of depth to cavity, depth to bedrock, and number of cavities per borehole. No highly clustered large cavities were detected by the General Gstatistics. Additionally, distances to the first through the nineth nearest neighbors were determined for cavities in different lithological materials and geographical clusters. Outcome of these spatial correlations and statistical analysis can be used to conduct risk assessment and the probability of occurrences of cavities in the future.

\section{Introduction}

Presence of solution cavities of different sizes poses major engineering problems in some areas of Abu Dhabi City Municipality (ADM) underlain by soluble rocks such as gypsum, calcarenite, or mudstone. This is especially critical if they are located at a relatively shal- 
low level. Sometimes halite, gypsum, or carbonate-rich unconsolidated crystalline formations dissolve when the groundwater condition changes, especially if originally unsaturated (Tose and Taleb, 2000). When the sediment layer starts losing material due to these reasons, insoluble fine sediments can also be washed out leading to bigger voids. Unconsolidated sediments can displace into cavities if the roof of the cavity collapses or is punctured by human activities such as drilling. Loss of unconsolidated sediments, due to washing out or leaking into cavities, is also a common problem in the region. These types of problems are likely to cause settlement or sudden soil collapse. Likewise, unconsolidated soil sediments are weakly cemented by soluble materials and can experience settlement or collapse if this weak bond is destructed by mechanical or chemical factors, such as excessive pressure or wetting (Hausmann, 1990).

Evaluation of the lithologic sections indicated that excavations periodically intercepted open voids in the mudstone and gypsum, and the loss of fluid circulation was commonly reported on drilling logs. Borehole data indicated that most of these cavities occur close to the top of the bedrock often at the interface between the overlying superficial deposits or sandstone and the underlying mudstone and gypsum. This formation of cavities is believed to be formed by groundwater movement along the interface of the mudstone and gypsum layers forming cavities that are more vulnerable to collapse in the vicinity of the top of rock (Farrant et al., 2012a).

Geohazard risk maps are currently available only for the Shakhbout City and Zayed City areas within the ADM. Most notably, Tose and Taleb (2000) developed a ground condition "risk" classification map for the former Shakhbout City and Zayed City areas. Although ostensibly designed to identify generally adverse subsurface conditions, Tose and Taleb's classification scheme correlated risk with shallow, less than $20 \mathrm{~m}$ or $66 \mathrm{ft}$ below ground surface [bgs], cavity distributions (heights) and so-called "broken subsurface strata" extents, as inferred from extensive geotechnical boring and geophysical survey data.

A similar, relatively simplified, cavity-based geotechnical risk classification map was developed by local practitioners for a discontinuous 44-plot area located within Shakbout City (Spektra Jeotek, 2011; 2012). On this map risk distribution was based solely on cavity (void) density and depth below ground surface. An overall low-risk classification was ascribed to individual plots in which voids were determined to be located more than $16 \mathrm{~m}$ or $52 \mathrm{ft}$ below the ground surface. In contrast, high risk was ascribed to plots in which "ground flaws" (including voids and water-loss instances) were largely confined to depths between $3 \mathrm{~m}(10 \mathrm{ft})$ and $10 \mathrm{~m}(33 \mathrm{ft})$; no voids were located shallower than $3 \mathrm{~m}(10 \mathrm{ft})$. Hazard within any class (low, medium, or high) was in turn determined by inferred cavity densities. Specifically, very low-risk conditions were assigned to individual plots with no more than three deep cavities. Moderately lowrisk conditions were similarly assigned to plots with less than 10 (more than 3) deep cavities. Slightly higher but still generally low-risk conditions were assigned to plots containing abundant (more than 10) but deep cavities.

These existing classification schemes did not consider other significant cavity stability factors; such as cavity cover thickness, overburden lithology and mechanical characteristics, hydrogeologic conditions, and groundwater geochemistry due to lack of data availability.

\section{Study Area}

Abu Dhabi is located in the stable cratonic region of the Arabian Plate. The study area covers an area of 11,000 square kilometers (4,250 square miles). It includes the mainland urban area of Abu Dhabi in addition to the coastal islands. Based on data availability the extent of study area was chosen as shown in Figure 1. The coastal area is relatively flat. Topographic elevation rises to approximately $35 \mathrm{~m}(115 \mathrm{ft})$ above sea level to the east and southeast across an arcuate 'escarpment' trending from Mafraq in the south to Al Shahama in the north (Price et al., 2012). Almost the entire urbanized Abu Dhabi City including many of the coastal islands is reclaimed land covered by backfill material. The backfill is found mostly in places in an uncontrolled way over pre-existing, coastal barrier and supratidal sabkha sediments.

The sedimentary sequence underlying the region consists of a relatively flat-lying assemblage of Paleozoic through Cenozoic carbonates and evaporites with interbedded clastic horizons to a thickness of approximately 8,000 $\mathrm{m}$ or $26,250 \mathrm{ft}$ (Al-Jallal and Alsharhan, 2005). Above this are extensive Holocene aeolian deposits forming the sand dunes of the Rub' al Khali, as well as localized sabkha sequences. A sabkha is defined as a flat area prone to periodic inundation and evaporate depositions, dominated by carbonates or sulphates (Al-Farraj, 2005). They are commonly formed in arid shallow-shelf environments, and are formed in response to two environmental conditions: deflation of sedimanet surfaces and sediment accumulation in a lagoon, or by a combination of both processes (Evans, 1970). Most of the solution cavities occur in the Gachsaran Formation part of the Neogene system (Alsharhan and Narin, 1997). The Gachsaran Formation is a thick evaporitic basinal succession that was deposited in a shallow marine/brackish setting with input from a nearby land source indicated by plant mat- 


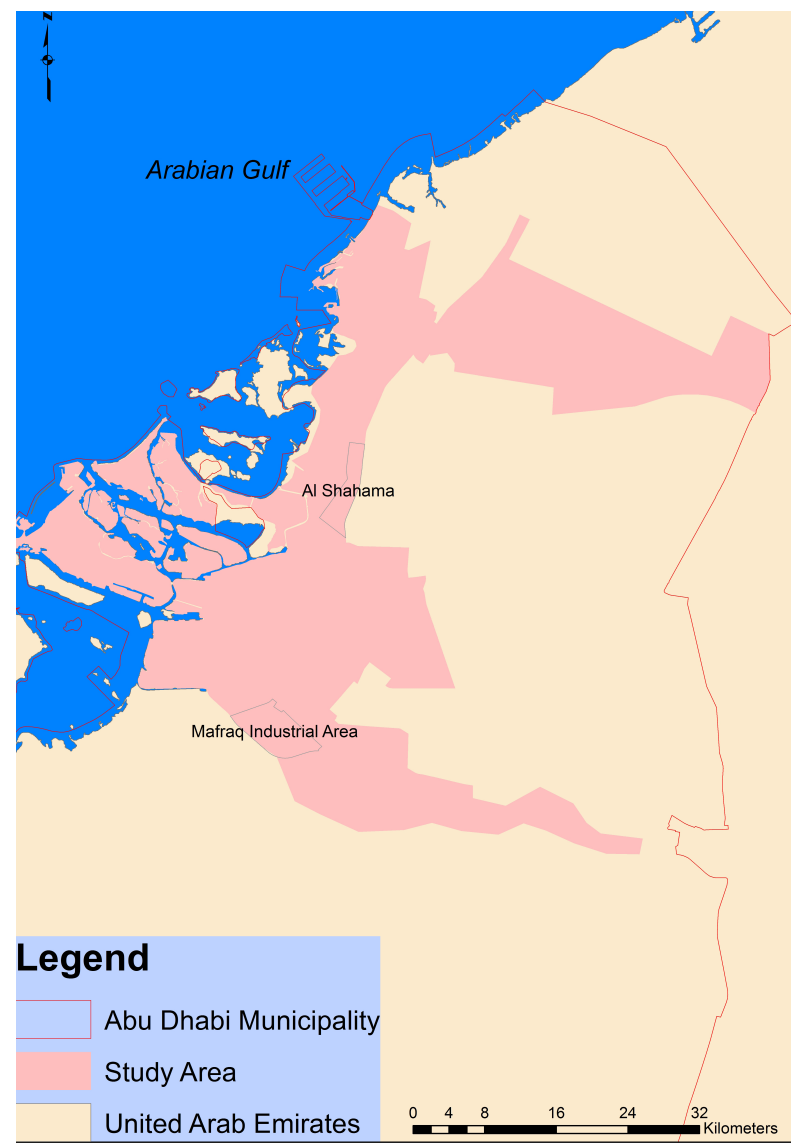

Figure 1. The extent of the study area shown here was decided based on the availability and spatial distribution of data within the ADM.

ter. It is well known from offshore oil wells, but is only poorly exposed onshore in the Abu Dhabi Area where it is recorded in numerous temporary excavations and boreholes that have penetrated up to $100 \mathrm{~m}(328 \mathrm{ft})$ of interbedded mudstone and gypsum (Farrant et al., 2012a). The Gachsaran Formation is covered by the Abu Dhabi Formation along the coast, and by younger Miocene and Quaternary sediments inland. Small exposures occur around Mafraq, Shakbout City, Shahama, Al Bahya, and along the foot of the Dam Formation escarpment around the Al Dhafra Air Base at Al Maqatrah (Farrant et al., 2012a, b). In many exposures and borehole logs the gypsum layers have been shown to contain well-developed dissolution cavities. The majority of these cavities are observed at or close to the surface of the bedrock, particularly at the interface between the superficial deposits and the underlying mudstone and gypsum (Farrant et al., 2012a). Figure 2 shows the extent and depth to Gachsaran Formation within the study area.

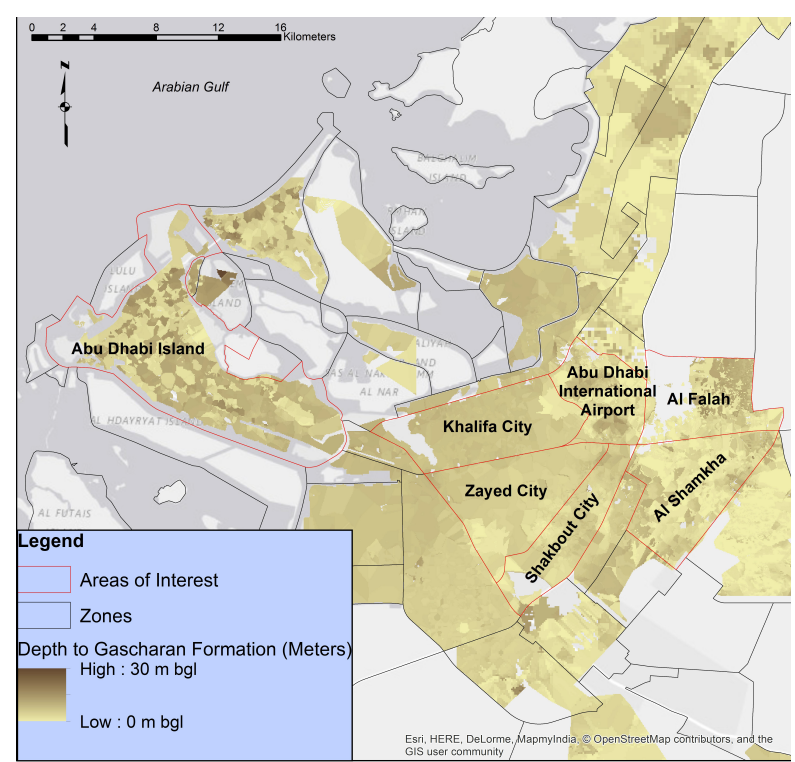

Figure 2. The areal extent and vertical depth of the Gachsaran Formation below ground surface level.

\section{Abu Dhabi Cavity Characteristics and Distribu- tion}

The ADM maintains a borehole database consisting of around 21,000 geotechnical borings. This borehole database is called Geotechnical Information Management System (GIMS). The GIMS for Abu Dhabi City supports a consolidated geotechnical database in accordance with internationally accepted standards. For this study, the GIMS borehole dataset was queried for string drops (also recorded as 'free fall of drilling rod' in the field logs) or loss of water, which are indicators of voids or cavities within a given boring. Since these are only indicators of the presence of subsurface cavities and voids for the purpose of this study it is assumed that these indicators are in fact subsurface cavities and voids adopting a conservative approach. A detailed geophysical and ground exploration investigation should be performed for confirmatory and verification purposes. A preliminary geodatabase was developed to manage spatial data acquired during the data collection process of this study.

A total of 1201 cavities are identified by querying "string drop", "free fall" or "loss of water" the GIMS borehole data. However, some boreholes may encounter multiple string drop, free fall, or loss of water features. The top most cavity for each borehole is used for the cavity hazard assessment for this phase of the GGHIP. Therefore, a total of 729 cavities nearest to the surface for each borehole were selected for analysis. Overburden thick- 


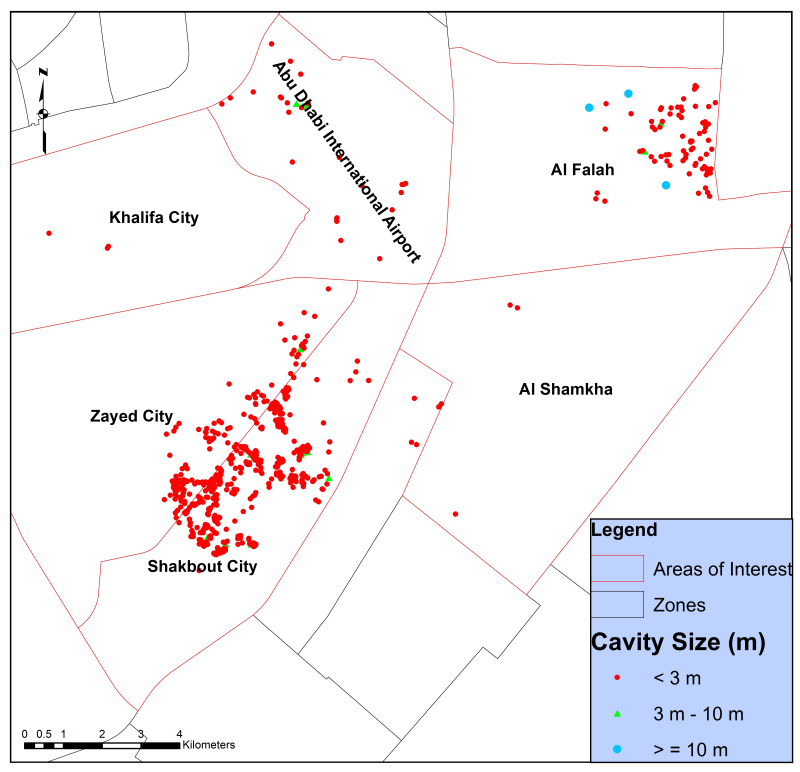

Figure 3. Spatial distribution of cavities in the Abu Dhabi Municipality.

ness or depth to bedrock, depth to cavity, cavity density, cavity size, and point pattern analysis were used to conduct hazard assessment for this project. The majority of cavities $(67 \%, 806$ out of 1201 cavities) occurred in the Shakbout area. Other areas where significant number of cavities occurred included the southeastern Capital District, the Abu Dhabi International Airport, and the Al Falah areas. A small number of cavities were sparsely distributed in other areas. All cavities were grouped into geographic clusters and lithological clusters for subsequent statistical analysis. Figure 3 shows the spatial distribution of cavities in the ADM.

The occurrence of cavities in different types of lithological materials in the ADM area is shown in Table 1. Figure 4 shows a chart representation of Table 1. Most cavities $(87 \%)$ occur in Mudstone, Gypsum, or at an interface between these two rock types, which compose part of the Gachsaran Formation (Ga). The Gachsaran Formation is a thick evaporitic basinal succession consisting of carbonates and evaporites, with marls and thin limestone (Bahroudi and Koyi, 2004). It does not form natural outcrops at surface (Farrant, A.R., et al., 2012). However, the dissolution of carbonate and evaporites within this formation causes subsurface voids formed in the ADM area. Even though some voids occurred in non-soluble rocks such as siltstone and sandstone, they were most likely associated with the dissolution of Gachsaran Formation underneath. Since the Gachsaran Formation is so extensive in the ADM area soil and sediment above the Gachsaran Formation can migrate down into voids and

\begin{tabular}{|c|c|}
\hline Lithological materials & Number of Cavities \\
\hline Calcareous Siltstone & 10 \\
\hline Gypsum & 270 \\
\hline Mudstone & 209 \\
\hline Siltstone & 21 \\
\hline Sandstone & 28 \\
\hline Calcarenite & 1 \\
\hline Soil & 8 \\
\hline *Gypsum - Muds tone Interfaces & 162 \\
\hline${ }^{*}$ Other Interfaces & 20 \\
\hline \multicolumn{2}{|c|}{ 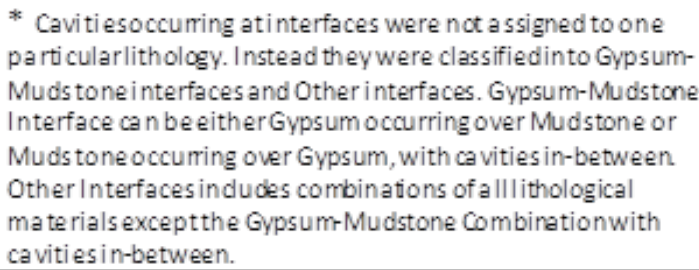 } \\
\hline
\end{tabular}

Table 1. Cavity distribution in different lithological materials.

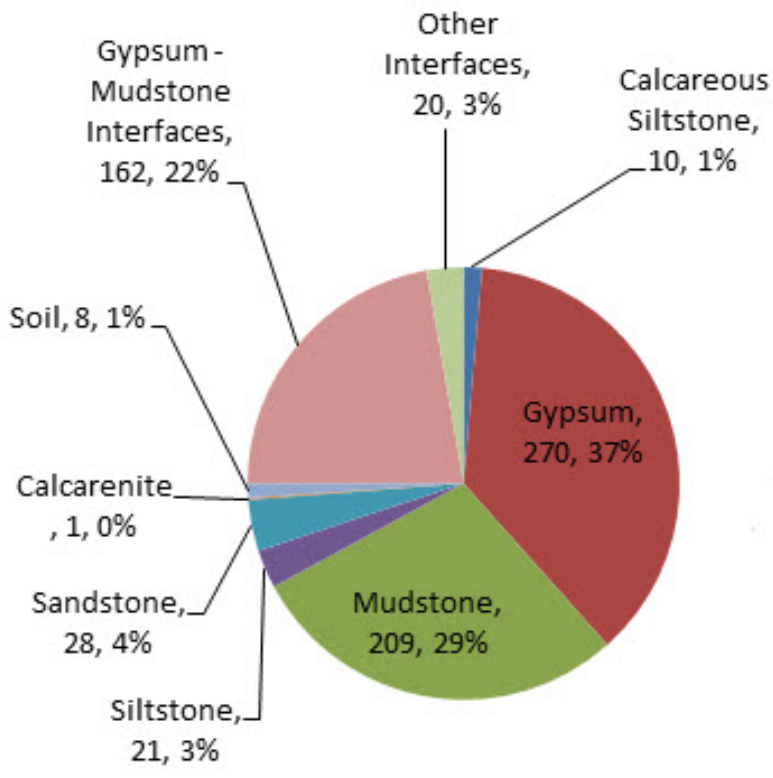

Figure 4. Cavity distribution in different lithological materials. Chart showing the occurrence of cavities in different types of lithologies prevalent in the ADM.

fractures of the soluble rocks through suffosion or piping processes. Therefore, the depth to the Gachsaran Formation would be an important criterion for cavity hazard assessment. Other reasons for occurrence of voids in insoluble materials could be due to drilling activities due to weak material collapsing. 
Mudstone has the second highest distribution of cavities among the other lithological material in the ADM. Even though gypsum is known to be more soluble than mudstone, mudstone layers generally have low compressive strength compared to gypsum layers. The mudstone in $\mathrm{ADM}$ is characterized as highly weathered with intact compressive strength as low as $100 \mathrm{kPa}$ which is less than $2 \%$ of the lowest intact compressive strength of the gypsum core samples tested. Three factors can be attributed to weathering and cavity formation in the mudstone: repeated cycles of wetting-drying; the highly weathered nature of the encountered mudstone, given the fact that it is made of fine-grained sedimentary rock of lightly cemented clay and silt, will enhance fines washout from rain infiltration and groundwater flow; and lastly dissolution-crystallization of relatively soluble minerals of gypsum interbedded within the mudstone (Canton et al., 2001).

\section{Point Pattern Analysis}

Many attempts have been made in the past to study patterns among point data in various natural systems. Clark and Evans (1954) and Thompson (1956) developed a nearest-neighbor analysis (NNA) method which has been used in many research areas. Another study (Drake and Ford, 1972) analyzed the patterns among two generation of sinkholes in Mendip, England by comparing the mean distances of the first to the twelfth nearest neighbors between the two generations of sinkholes.

A comprehensive investigation of cavity distribution is critical to conduct hazard assessment in the ADM area. Point pattern analysis is the first step to examine if the cavities are clustered or randomly distributed. Depth to bedrock, depth to cavities, cavity density, cavity size or thickness, and distributions of cavities in different geographic and lithological clusters help to characterize locations where cavities would likely occur. Pattern analysis is the study of the spatial arrangement of point features in two-dimensional space (Gao, 2002). ArcMap provides tools to analyze point pattern distribution that can be used to determine clustering or level of dispersion among the different data points based on the size of the study area. The Average Nearest Neighbor tool measures the distance between each feature centroid and its nearest neighbor's centroid location. It then calculates the average of all these nearest neighbor distances. If the average distance is less than the average for a hypothetical random distribution, the distribution of the features being analyzed is considered clustered (Ebdon, 1985).

The Spatial Autocorrelation (Global Moran's I) tool measures spatial autocorrelation based on both feature locations and feature values simultaneously. Given a set of features and an associated attribute, it evaluates whether the pattern expressed is clustered, dispersed, or random (Getis and Ord 1992; Griffith, 1987). The High/ Low Clustering (Getis-Ord General G) tool measures the concentration of high or low values for a given study area. The High/Low Clustering tool is most appropriate when there is a fairly even distribution of values and unexpected spatial spikes of high values need to be identified (Mitchell, 2005).

\section{Results}

A pattern analysis usually demonstrates if a distribution pattern is random, dispersed, or clustered. In addition, a distribution pattern containing clusters of high or low values can also be identified by pattern analysis. This section discusses the results of the pattern analysis performed on the cavity dataset.

\section{Pattern Analysis in the Shakbout City Area}

Since the majority of cavities occurred in the Shakbout Area pattern analysis, including average nearest neighbor analysis; Moran's I for measuring spatial autocorrelation; and G-statistics for measuring high/low clustering, were conducted in this area using spatial statistics tools in ArcGIS. Figures 5 through 11 illustrate results of point pattern analysis of cavities in the Shakbout Area. Average nearest neighbor analysis (Figure 5) and Moran's I (Figure 6 ) show that cavities are strongly clustered in this area with high confidence level (>99\%). General G statistics identified high clustering (hot spot) of cavities with relatively high values of depth to cavity, depth to

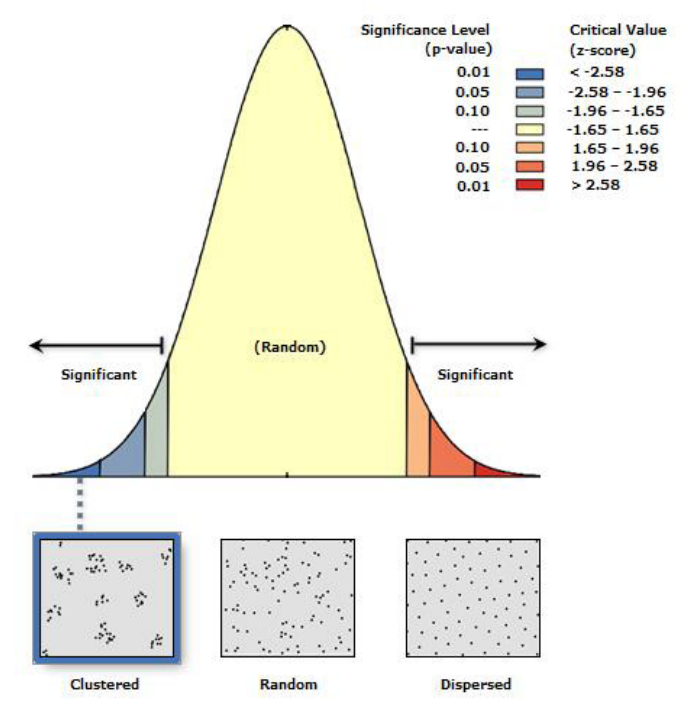

Figure 5. Shakbout Area - Average nearest neighbor analysis indicates a clustering pattern based on the p-value. 
bedrock, and number of cavities per borehole (Figures 8 and 9). No highly clustered large cavities were detected by the General G statistics (Figure 7).

\section{Pattern Analysis for Factors Influencing Forma- tion of Cavities}

Depth to Gachsaran Formation, depth to bedrock, depth to cavity, and cavity size distributions were conducted in three geographic clusters including the Shakbout City

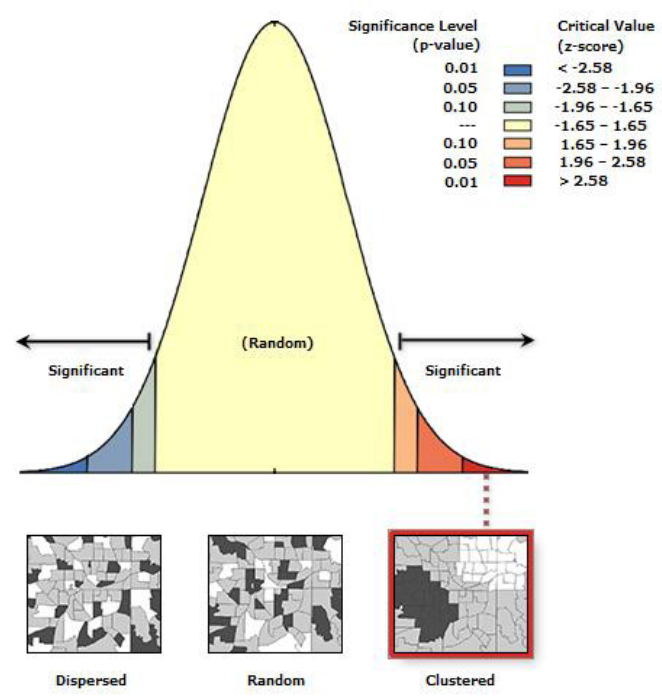

Figure 6. Shakbout Area-Moran's I with cavity size indicates a clustering of cavities with similar size.

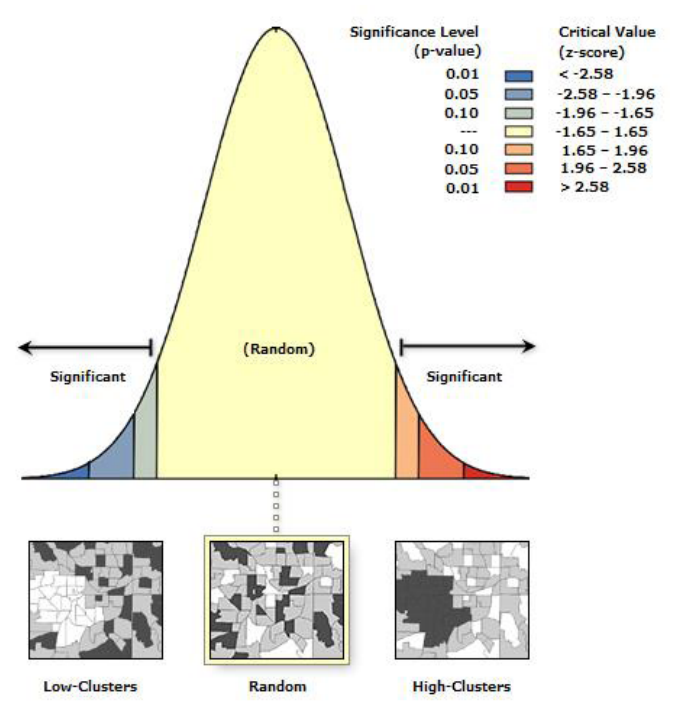

Figure 7. Shakbout Area - General $G$ with cavity size indicates large cavities are not clustered. and southeastern Capital District, the Abu Dhabi International Airport, and the Al Falah areas. Most cavities occurred in areas surrounding the Shakbout City area, including the southeastern Capital District area, and these areas represent typical geological settings for the cavity hazard assessment. Therefore, results of depth to bedrock, depth to cavity, and cavity size distributions for cavities within the Shakbout City and the southeastern Capital District area are discussed in this paper. Cavity

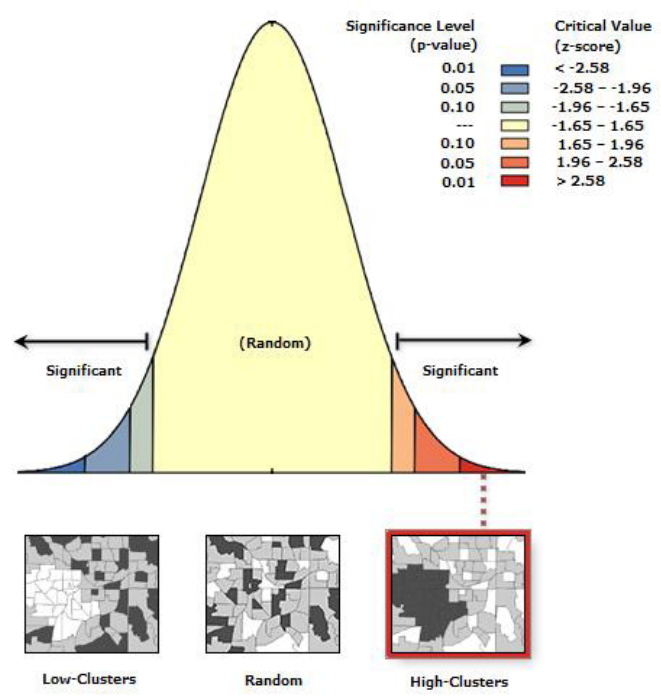

Figure 8. Shakbout Area - General $G$ with depth to cavity indicates cavities occurring at similar depths are clustered.

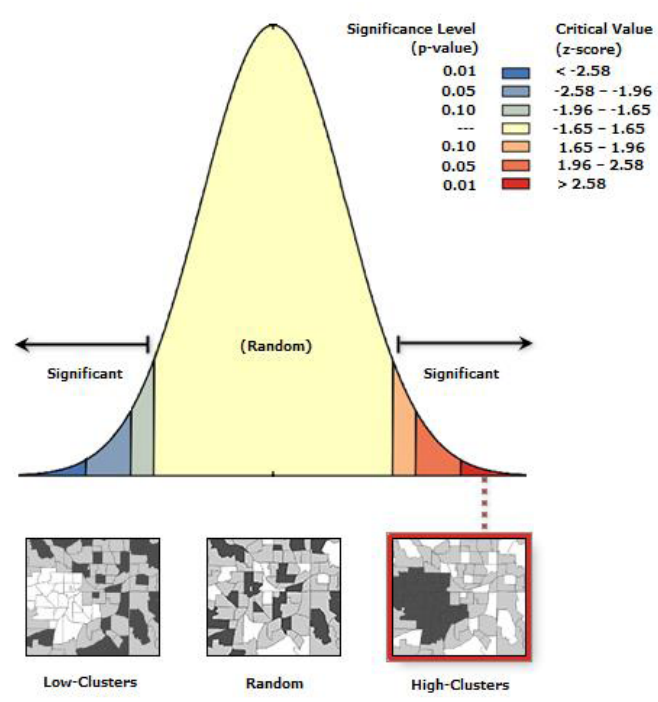

Figure 9. Shakbout Area-General $G$ with depth to bedrock indicates high clustering of cavities at certain depths to bedrock. 
size is a two-dimensional attribute represented by the thickness of each cavity or the distance between the top and bottom elevations of each cavity. Depth to Gachsaran Formation, depth to bedrock, and depth to cavity all follow normal distributions (Figure 10). Cavity size distribution (Figure 11) is more random similar to the Poisson distribution, which is consistent to results of the General G statistics (Figure 7).

\section{Nearest Neighbor Analysis}

Distances to the first through the nineth nearest neighbors were conducted for cavities in different lithological materials and geographical clusters. Figure 12 demonstrates a histogram of the distance to the nearest cavity within the Gachsaran Formation. The median distance
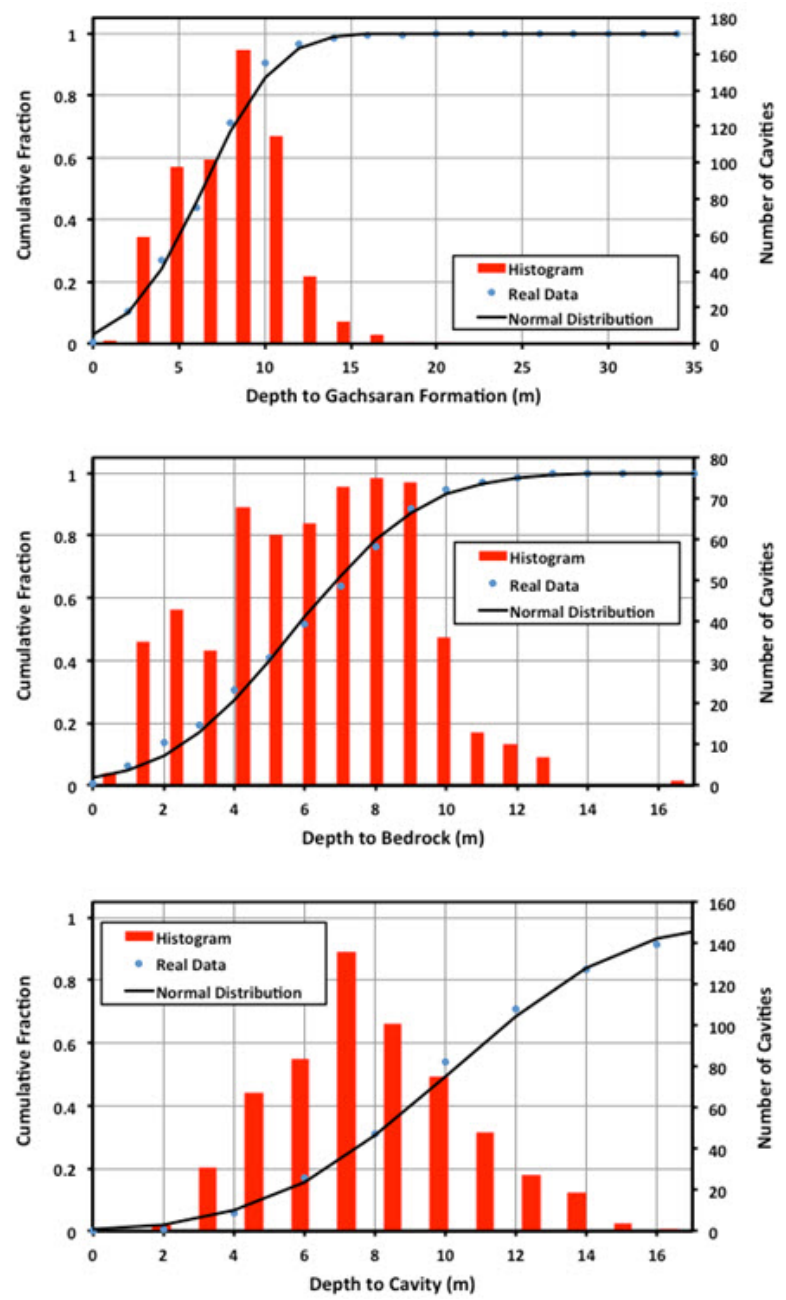

Figure 10.

Cavity distribution in relation to depth to Gachsaran Formation, depth to bedrock and depth to cavity follow a normal distribution. to the first through the nineth nearest cavity is linearly increasing within the Gachsaran Formation (Figure 12).

For nearest neighbor analysis of the entire ADM area, some cavities may have a nearest neighbor that lies outside of the district boundaries or areas without detailed borehole data. This phenomenon is called edge effect. To avoid edge effects, cavities were evaluated for proximity to district boundaries or areas without enough borehole data. Some isolated cavities are very far away from the main populations. These areas have not been fully investigated and some cavities might exist, but may not be mapped or recorded in the database. Three kinds of cavities were removed for NNA: cavities that have nearest neighbors outside of the clustered area whose distance
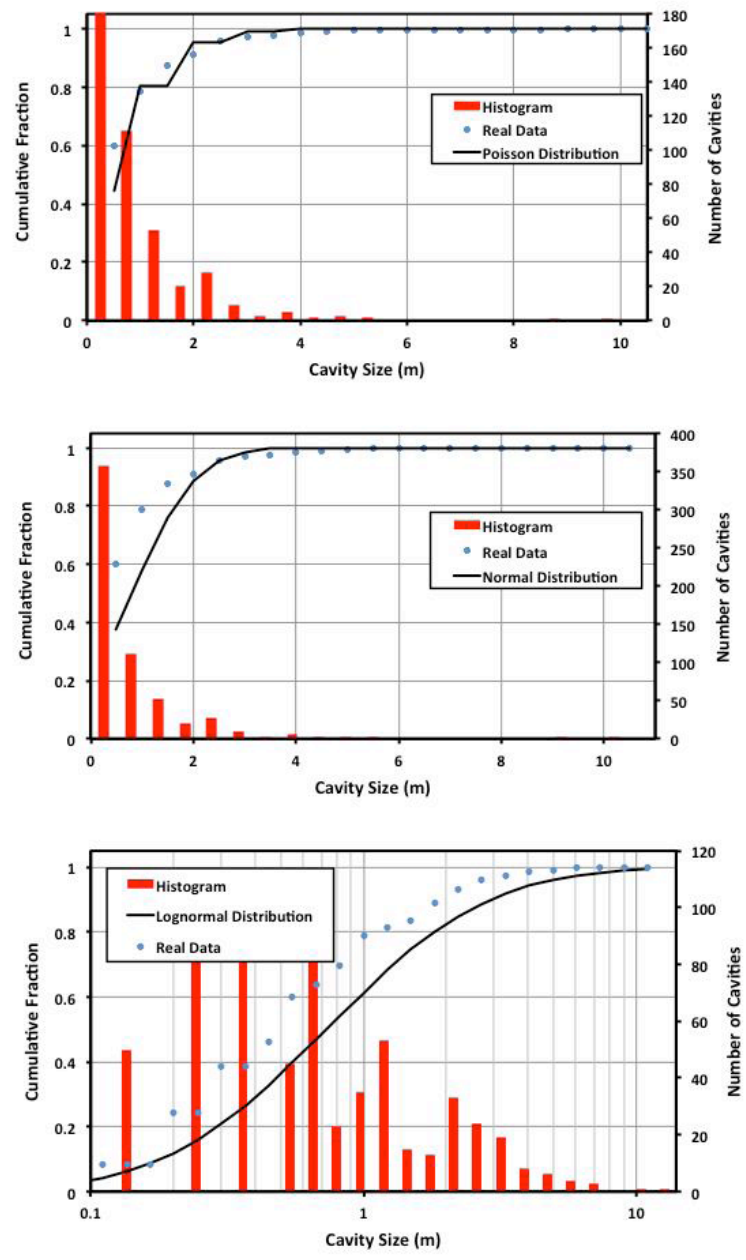

Figure 11.

Cavity distribution in relation to cavity size follows poisson distribution indicating a random spatial distirbution. 

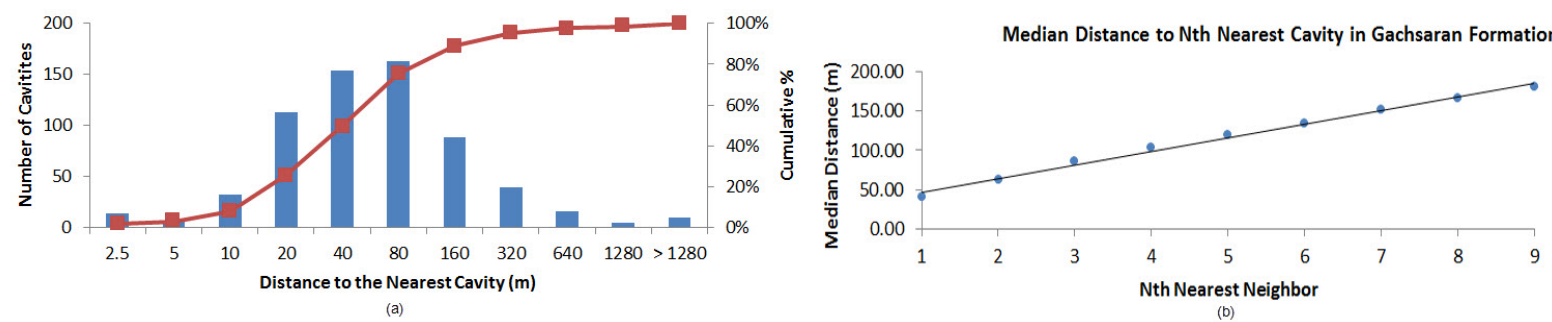

Figure 12. (a) Distance to the Nearest Cavity and (b) Median Distance to the Nth Nearest Cavity within the Gachsaran Formation.

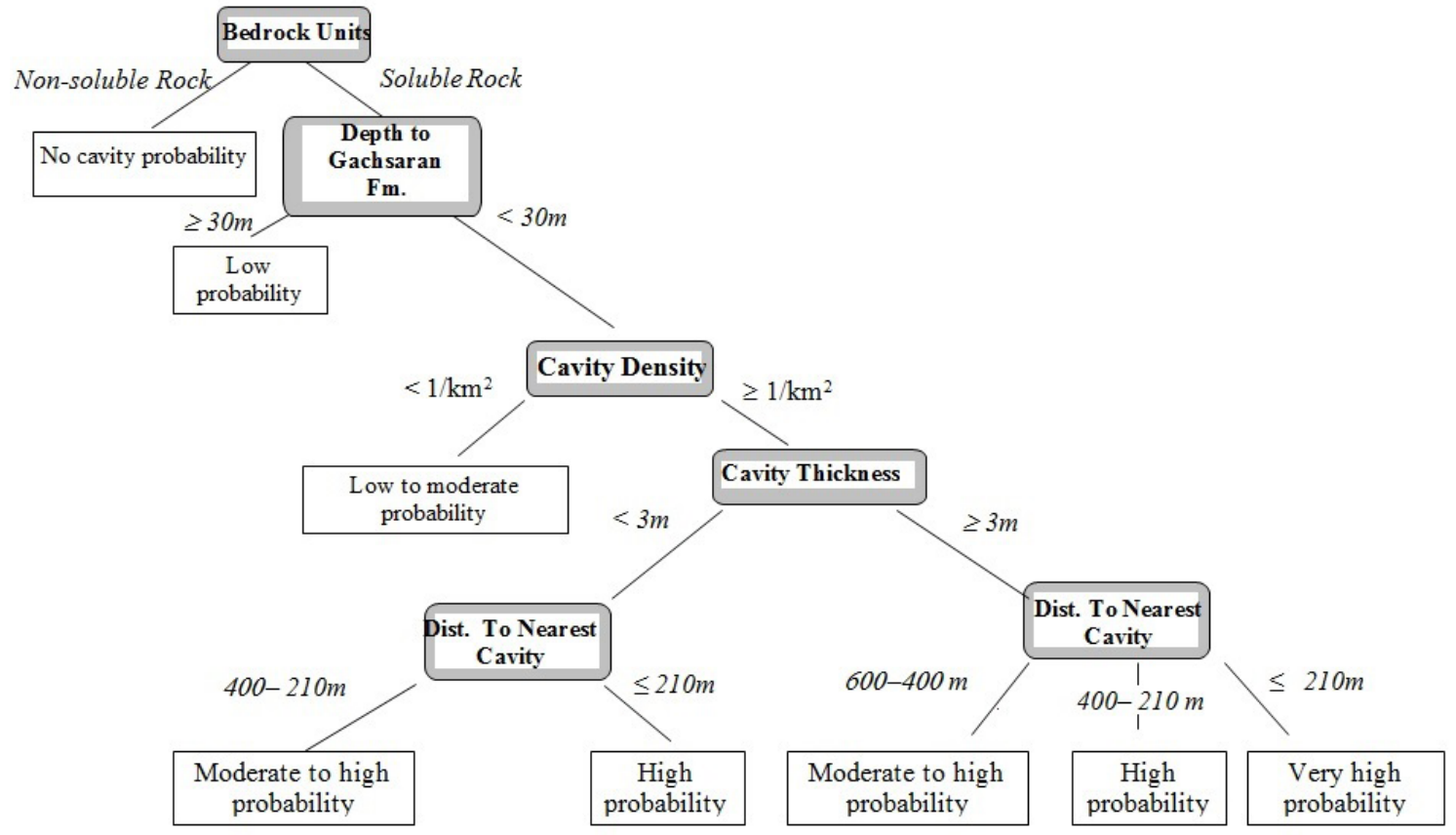

Figure 13.

The decision tree model that was developed for hazard assessment related to cavities in the ADM area.

to the nearest neighbor $(\mathrm{DNN})$ patterns are significantly different from those in the clustered area, cavities whose DNN are greater than the distance to the boundary of the project area, and some isolated cavities whose neighborhood has not been fully investigated for cavities by boreholes. The overall DNN distribution of all cavities does not follow Poisson, Normal, or Log-Normal distributions. However, the distribution of the DNN for all cavities more or less follows normal distribution once DNN is greater than $160 \mathrm{~m}$.

A decision tree model based on cavity characteristics and the distributions of cavities was developed for hazard assessment in the ADM area (Figure 13). The decision tree includes characteristics of bedrock geology, depth to the
Gachsaran Formation, cavity density, cavity size, and distances to the nearest cavities in the ADM area. The primary controls on cavity development are lithostratigraphic position or bedrock geology and depth to the soluble Gachsaran Formation.

\section{Conclusions}

It is evident that soluble bedrock is definitely prone to cavity formation in comparison to insoluble rock, as majority of the cavities occurring in insoluble rock such as mudstone can be attributed to its weak compressive strength properties (Canton et. al, 2001). Out of the various soluble bedrock formations within the ADM the Gachsaran Formation has the highest likelihood for cavity formation. Cavities are formed either due to the dis- 
solution of mudstone or gypsum layers in the formation, or at weak and weathered zones present at the interface between these two lithological materials. It is also evident that more cavities are likely to be formed in regions with shallow bedrock than in regions with relatively deeper bedrock.

Based on the cavity distribution in relation to depth to Gachsaran Formation (Figure 10) it is more likely that cavities are formed in locations where the Gascharan formation occurs at a depth of less than $30 \mathrm{~m}(100 \mathrm{ft})$ below ground surface. Similarly, based on the histogram for distribution of cavities in relation to cavity size (Figure 11), it is statistically more likely that a cavity prone region develops smaller sized cavities (less than $3 \mathrm{~m}$ or $10 \mathrm{ft}$ thick) than larger sized cavities (greater than or equal to $3 \mathrm{~m}$ or $10 \mathrm{ft}$ in thickness). The majority of the cavity population tends to form in highly concentrated zones indicating that neighborhood effect plays a very important role in cavity distribution and formation.

The decision tree model quantifies depth to Gachsaran Formation, depth to cavity, cavity density and distances to the nearest cavity in the Abu Dhabi Municipality. This decision model, when compared with earlier, elementary versions of zone level cavity risk assessment studies, produces a more structured and objective approach towards analyzing patterns in the spatial distribution of cavities and supplements the existing cavity distribution maps when comparing the depth and resolution of evalution. However, other influential parameters controlling formation of cavities, such as groundwater chemistry and fluctuation; land use and topography; and anthropogenic changes to landscape and groundwater, were not considered in the study due to the lack of sufficient data. While this decision tree model defines certain quantitative requisites for determining regions that are more susceptible to forming cavities, this decision process can only predict future occurrence of cavities with low accuracy as information relating to all cavities used in this study are solely collected from boring logs. This contributes to a lot of noise in the accuracy of cavity distribution. Also, in this study cavities are assumed as discontinuous $2 \mathrm{D}$ features, while in reality cavities tend to develop and propagate in vertical and lateral directions. Therefore, this decision tree model needs to be constantly updated and verified as newer site investigation studies are performed and made available.

\section{References}

Al-Jallal, I.A. and A.S. Alsharhan. 2005. Arabia and the Gulf. In: R.C. Selley, L.R. Cocks, and I.R. Plimer Ed. Encyclopedia of Geology Vol. 1. Amsterdam
(The Netherlands): Elsevier Science B.V. p. 140152.

Alsharhan AS, Nairn AEM. 1997. Sedimentary basins and petroleum geology of the Middle East. 1st ed. Amsterdam (AE): Elsevier Science B. V. p. 441.

Bahroudi, A., and Koyi, H A. 2004. Tectonosedimentary framework of the Gachsaran Formation in the Zagros foreland basin. Marine and Petroleum Geology 21: 1295-1310.

Clark PJ, and Evans, FC. 1954. Distance to nearest neighbor as a measure of spatial realtionships in populations. Ecology 35: 445-453.

Canton, Y.; Sole-Benet, A.; Queralt, I.; and Pini, R. 2001. Weathering of a gypsum-calcareous mudstone under semi-arid environment at Tebernas, SE Spain: laboratory and field-based experimental approaches. Catena 44: 111-132.

Drake JJ, and Ford, DC. 1972. The analysis of growth pattersns of two-generation populations: the example of karst sinkholes. Canadian geographer XVI (4): 381-384.

Ebdon, David. 1985. Statistics in Geography. Blackwell. Farrant, AR, Ellison, RA, Merritt, JW, Merritt, JE, Newell, AJ, Lee, JR, Price, SJ, Thomas, RJ, and Leslie, A. 2012. Geology of the Abu Dhabi 1:100 000 map sheet. United Arab Emirates (Keyworth, Nottingham: British Geological Survey). ISBN 9780852727256.

Farrant, AR, Ellison, RA, Merritt, JW, Merritt, JE, Newell, AJ, Lee, JR, Price, SJ, Thomas, RJ, And Leslie, A. 2012. Geology of Al Wathba 1:100 000 map sheet. United Arab Emirates (Keyworth, Nottingham: British Geological Survey). ISBN 9780852727225.

Gao Y, Alexander EC Jr. 2008. Sinkhole hazard assessment in Minnesota using a decision tree model. Environmental Geology 54 (5): 945-956.

Gao, Y. 2002. Karst Feature Distribution in Southeastern Minnesota: Extending GIS Based Database for Spatial Analysis and Resource Management [Dissertation]. Minnesota (MN): University of Minnesota. p. 210.

General Geotechnical Investigation Report (Draft), Spektra Jeotek, 2012, Presidential Affairs Building, Khalifa City-B. February 162012.

Geotechnical Risk Map, Presidential Affairs 44 Plots Khalifa City-B. Spektra Jeotek, 2011, Abu Dhabi, UAE.

Getis, Arthur, and J. K. Ord. 1992. The Analysis of Spatial Association by Use of Distance Statistics. Geographical Analysis 24 (3).

Griffith, Daniel. 1987. Spatial Autocorrelation: A Primer. Resource Publications in Geography, Association of American Geographers. 
Hausmann, M.R., 1990, Engineering Principles of Ground Modification. McGraw-Hill Publishing Company.

Mitchell, Andy, 2005. The ESRI Guide to GIS Analysis Volume 2. ESRI Press.

Price SJ, Farrant AR, Leslie A, Terrington RL, Merrit J, Entwisle D, Thorpe S, Horabin C, Gow H, Self S, and McCormick T. 2012. A 3D superficial and bedrock geological model of the Abu Dhabi urban area. United Arab Emirates. British Geological Survey Commercial Report CR/11/138.

Thompson HR. 1956. Distribution of distance to n-th nearest neighbor in a population of randomly distributed individuals: Ecology 37: 391-394.

Tose JA, Taleb A, 2000. Khalifa city 'b' ground conditions program. In: Mohamed \& Al Hosani, editors. Georngineering in Arid Lands. Balkerna (Rotterdam). p. 75-81. 